\title{
Evaluation of Topical Dispenser Systems for Vaginal Delivery of Feminine Medications
}

\author{
Chanelle Toerien-Hayes ${ }^{1}$, Quy Nguyen ${ }^{2}$, Joy Woods $^{2}$, Qiang Liu ${ }^{1}$, Thomas Kupiec ${ }^{1}$, Nicole Vu ${ }^{1,}$ * \\ ${ }^{1}$ Analytical Research Laboratories (ARL) Bio Pharma, Oklahoma City, USA \\ ${ }^{2}$ University of Oklahoma Health Sciences Center College of Pharmacy, Oklahoma City, USA
}

Email address:

nvu@arlok.com $(\mathrm{N} . \mathrm{Vu})$

${ }^{*}$ Corresponding author

To cite this article:

Chanelle Toerien-Hayes, Quy Nguyen, Joy Woods, Qiang Liu, Thomas Kupiec, Nicole Vu. Evaluation of Topical Dispenser Systems for Vaginal Delivery of Feminine Medications. American Journal of Internal Medicine. Vol. 7, No. 4, 2019, pp. 93-101. doi: 10.11648/j.ajim.20190704.13

Received: May 17, 2019; Accepted: June 25, 2019; Published: August 5, 2019

\begin{abstract}
The vaginal route of administration has a large surface area with a rich blood supply demonstrating capacity for local absorption and systemic bioavailability of drugs. However, there are problems associated with current vaginal delivery method in terms of dosing precision and accuracy. In this report, the potential utility of the metered-dose Topi-CLICK ${ }^{\circledR}$ Perl $^{\mathrm{TM}}$ system for vaginal delivery of feminine medication is presented. The aim was to evaluate the efficiency of Topi-CLICK ${ }^{\circledR}$ Perl $^{\mathrm{TM}}$ for dosing accuracy, precision, and residual waste of medicaments relative to currently available dispensing systems. The results showed Topi-CLICK ${ }^{\circledR}$ Perl $^{\mathrm{TM}}$ system to have the highest accuracy for a dose being correctly delivered more than $88 \%$ of the time. Whereas other commonly used dispenser systems, such as plastic or metal (aluminum) ointment tubes with smooth or ribbed applicators, exhibited not more than $10 \%$ of doses being within acceptable limits for accuracy. Medication waste was significantly minimized using Topi-CLICK ${ }^{\circledR} \mathrm{Perl}^{\mathrm{TM}}$, which has an estimated overfill volume less than $6 \%$. This required overfill volume ranged from $39 \%$ to $88 \%$ respectively, for the plastic and metal ointment tubes. Qualitatively, operators of TopiCLICK $^{\circledR}$ Perl $^{\mathrm{TM}}$ found the metered-dose system the easiest to use with little mess. Based on these results, Topi-CLICK ${ }^{\circledR}$ Perl $^{\mathrm{TM}}$ outperformed other traditional dispensing systems for vaginal drug delivery in accuracy and precision, with the least amount of residual medication waste.
\end{abstract}

Keywords: Topical Dispenser, Vaginal Drug Delivery, Feminine Product, Metered-dosing Device, Vaginal Applicator, Topi-CLICK ${ }^{\circledR}$ Perl $^{\mathrm{TM}}$, Ointment Tube

\section{Introduction}

There are several routes of administration for which drugs can be delivered to the body. One of the more unconventional methods is the intra-vaginal drug delivery, using varieties of dosage forms such as pessaries, tablets, rings, gels, foams and creams [1]. The vaginal route was traditionally reserved for locally acting agents such as antibacterial, antifungal and spermicidal agents, but it offers a great potential for systemic delivery. This area has a rich blood supply, a large surface area, and a wide range of permeability for different compounds, which makes it a potentially ideal site for administration of systemic drugs [2, 3]. There are some advantages of vaginal drug delivery, for example, it by- passes first pass metabolism in the gastrointestinal (GI) tract and liver, increases bioavailability, and has a quick onset of action [4]. The GI effects such as nausea and vomiting that is prevalent with most oral medication are also reduced. Currently, intra-vaginal medications are used for contraception, hormone replacement therapy, cervical cancer treatment, and anti-fungal therapy among others [5-8]. Vaginal dapivirine rings have recently been studied for use as HIV prevention in women [9].

Concerns regarding the effectiveness of intra-vaginal therapy do exist. Typically, treatment of these conditions requires daily application and therefore, consumer convenience must be taken into consideration to support patient adherence [10]. A patient's daily schedule, activity, innate capability, ease of treatment application as well as their 
relationship with their physicians and pharmacists, each plays a role in the successful completion of their prescribed therapy $[11,12]$. To further encourage adherence, medication packaging and delivery systems should be suitable for portability and user-friendliness. In addition, incidences such as leakage, messiness and low residence time are obviously unfavorable $[1,10]$.

Leaky devices or devices with large amounts of undeliverable residual drug left inside the dispenser are among problems associated with conventional dispenser systems. Any residual cream that could not be dispensed is wasted product and represents added cost to compounders and to end users of the product. This added cost is significant for patients on expensive prescriptions such as Estrace vaginal cream, which is priced at $\$ 8.89$ per gram. One box contains 42.5 grams of cream, costing approximately $\$ 337$ [13]. Reducing waste would be highly beneficial for patients and pharmacists.

However, major concerns associated with conventional drug delivery devices are the accuracy and precision of applying the correct dose. This is particularly true since the vaginal site is a harder to access area of the body for drug administration. Metered dispensing systems may be part of the solution for this patient population in dispensing the same amount of product each time. Having a precise method of measuring a fixed amount of medication would change how the drug is ultimately presented to the patient, thereby maximizing positive patient outcomes.

The objective of this study was to evaluate the accuracy, precision, and residual medication of the Topi-CLICK ${ }^{\circledR}$ Perl $^{\mathrm{TM}}$ system and other conventional dispensers for vaginal administration of drugs.

\section{Materials and Methods}

\subsection{Study Overview}

The study evaluated five different types of loader and applicator combinations: A) Topi-CLICK ${ }^{\circledR}$ Perl $^{\mathrm{TM}}$ loader with $\mathrm{Perl}^{\mathrm{TM}}$ applicator, B) plastic ointment tube with a ribbed applicator, C) plastic ointment tube with a smooth applicator, D) metal (aluminum) ointment tube with a ribbed applicator, and E) metal (aluminum) ointment tube with a smooth applicator. In addition to quantitative performance evaluations, a secondary objective of the study was to measure ease-of-use based on operator observations. The Topi-CLICK $^{\circledR}$ Perl $^{\mathrm{TM}}$ loader is a metered-dose dispenser that dispenses $0.25 \mathrm{~mL}$ cream per actuation or per click. The $\mathrm{Perl}^{\mathrm{TM}}$ applicator snaps onto the top of the loader, and the base on the loader is "clicked" the number of times needed to dispense the target volume of cream. In contrast, both smooth and ribbed applicators are screwed onto the top of metal or plastic dispensing tubes. The tubes are then squeezed to dispense cream until the barrel edge of the applicator is aligned with the desired dose marking on the plunger

\subsection{Experimental}

\subsubsection{Blinded Operators}

The operators or testers were two females and one male, who were blinded to the aim and data until all experimentation was completed. The operators were verbally instructed in the operation of each device. The operators were shown how to assemble the tubes and applicators, which are screw on systems, as well as the snap-on and snap-off action of the applicators for the Topi-CLICK ${ }^{\circledR}$ Perl $^{\mathrm{TM}}$ system; they also received a leaflet produced by the device's manufacturer, in which operation of the Topi-CLICK ${ }^{\circledR}$ Perl $^{\mathrm{TM}}$ vaginal dosing system is described in detail with accompanying illustrations. This leaflet is included in the final packaging of the product and is distributed to patients by their pharmacists.

\subsubsection{Test Systems and Cream}

A list of the dispenser systems evaluated in this study is provided in Table 1. The test systems included 2-ounce metal and plastic ointment tubes coupled with either smooth or ribbed applicators, and the Topi-CLICK ${ }^{\circledR}$ Perl $^{\mathrm{TM}}$ loaders with Topi-CLICK $^{\circledR}$ Perl $^{\mathrm{TM}}$ applicators. An oil-in-water (o/w) cream base commonly used for compounded hormone replacement and other vaginal treatments was used as a model cream to fill loaders for the dispensing test (Humco MultiBase cream; Total Pharmacy Supply Item\# 9919-10000006010).

\subsubsection{Preparation of Loaders and Applicators}

All loaders and applicators were weighed empty; whereafter loaders were filled by a compounding pharmacy with $35 \mathrm{~mL}$ of MultiBase cream. Weights of filled containers were recorded as filled weights for the loaders. Prior to testing, all loaders were primed to remove air in the headspace of the devices. The plastic and metal ointment tubes were tapped 20 times upside down (on their caps) on a hard surface to settle the cream in the top part of the tube. The metal seal of the metal tubes was pierced, and cream was pushed up the tube until a pea-size amount was dispensed, after which the tube was wiped and capped. The seal on the plastic tubes was removed before priming similarly to the metal tubes. The Topi-CLICK $^{\circledR}$ Perl $^{\mathrm{TM}}$ loaders were tapped 20 times on their bases to settle the cream; the base turned until only cream was expelled, and the device was wiped and capped.

Table 1. Loaders and applicators evaluated in the study.

\begin{tabular}{lll}
\hline Product Description & Supplier & Product Number \\
\hline Topi-CLICK $^{\circledR}$ Perl $^{\mathrm{TM}}$ Applicator with shell cap, 35 mL, white & DoseLogix & TCPerl $^{\mathrm{TM}} 02$ \\
Topi-CLICK $^{\circledR}$ Perl $^{\mathrm{TM}}$ Snap-On Vaginal Applicator, 4 mL, clear & DoseLogix & TCPerl $^{\mathrm{TM}} 03$ \\
2 oz. Aluminum Ointment Tube, \#16 orifice luer lock (Metal Tube) & Total Pharmacy Supply & 7354000000341 \\
2 oz. Plastic Ointment Tube, \#16 Neck & Total Pharmacy Supply & 7367000006656 \\
Smooth-Vaginal Cream Applicator 0-4 GM & Letco Medical Supplies & 690145 \\
Ribbed-Applicator, Vaginal Cream & PCCA & $35-1332-05 E A$ \\
\hline
\end{tabular}




\subsubsection{Dispensing Experiment}

The dispensing test was designed to assess dosing accuracy, ease of use, and potential waste of medicinal cream for a 30-dose prescription. Testing was performed in 30 cycles by each operator for each loader/applicator set. Three operators dispensed $1-\mathrm{mL}$ doses and one operator was assigned to dispense 4-mL doses. Each dosing cycle consisted of applicators filled in the following sequence: Topi-CLICK $^{\circledR}$ Perl $^{\mathrm{TM}}$; Plastic tube/Ribbed applicator; Plastic tube/Smooth applicator; Topi-CLICK ${ }^{\circledR}$ Perl $^{\text {TM }}$; Metal (aluminum) tube/Ribbed applicator; Metal (aluminum) tube/Smooth applicator. The Topi-CLICK ${ }^{\circledR}$ Perl $^{\text {TM }}$ system was tested twice (sets $1 \& 2$ ) since only Perl $^{\mathrm{TM}}$ applicators were used, while plastic and metal ointment tubes employed both smooth and ribbed applicators in the dispensing test.

Dispensing with the Topi-CLICK ${ }^{\circledR} \quad$ Perl $^{\text {TM }}$ system comprised attaching the $\mathrm{Perl}^{\mathrm{TM}}$ applicator and turning the base for 4 clicks (for the 1-mL dose) or 16 clicks (for the 4-mL dose), where each click turns the base plate $90^{\circ}$ and dispenses $0.25 \mathrm{~mL}$ of the cream. The filled applicator was removed from the loader after a waiting time of 2.5 minutes for the full dose to be delivered by the device. The high viscosity of MultiBase cream required an extended dispensation time to fill the $\operatorname{Perl}^{\mathrm{TM}}$ applicator.

The metal and plastic ointment tubes were in primed positions when applicators were screwed on. Pressure was then applied to the bases of the tubes to dispense MultiBase cream to the dose volume marked on the applicators. It took 2 minutes for a dose to be fully dispensed until the next dose was initiated. This was necessary to limit operators' fatigue and focus their attention.

The filled applicator was weighed by an unblinded experimenter. To avoid biases in operation there was no lineof-sight between the operator and the balance, and no feedback was given to the operators by the experimenter. Operators recorded their observations during each dispensing cycle, amongst which were ergonomics, consistency of dosing, ease of use, and any unexpected shifts in performance of the test system. A new applicator was used for each $1-\mathrm{mL}$ dose; they were then washed and dried for reuse in the 4-mL dispensing test.

\subsubsection{Dose Measurements}

Each loader was weighed empty (start weight) and weighed filled, prior to the dosing test. Fill volume $(\mathrm{mL})$ was calculated as (Filled Weight, g - Start Weight, g)/Density of the cream, $\mathrm{g} / \mathrm{mL}$ ). Loaders were also weighed after completion of 30 doses, and cumulative amount of MultiBase dispensed $(\mathrm{mL})$ was calculated as (Filled Weight, $\mathrm{g}-$ Weight after last dose, g)/Density of the cream, $\mathrm{g} / \mathrm{mL}$ ). Thereafter, loaders were emptied, and then weighed again to determine the amount of residual cream remaining in the evacuated loaders.

Applicators were weighed empty and weighed filled, and the delivered dose $(\mathrm{mL})$ was calculated as (Filled weight, $\mathrm{g}-$ Empty weight, g)/Density of the cream, g/mL).

\subsubsection{Determination of Density}

Determination of density for MultiBase cream under the test conditions is critical in the assessment of dosing accuracy. The dispenser systems tested are volumetric dispensers, but experimental data is obtained gravimetrically. To ensure accurate conversion of weight data to volume data, the density of MultiBase was verified using the following protocol.

Five units of each loader type were used. MultiBase cream was dispensed from the loader into a glass beaker, and air bubbles were removed by gently pushing the ribbons of cream together. The prepared cream was used to load a 3-mL syringe, which then filled a pre-weighed 1-mL syringe through a Rapidfill connector (Luer Lock-to-Luer Lock). Each loaded 1-mL syringe was capped, and centrifuged twice without the plunger at $1,000 \mathrm{x} \mathrm{g}$ (or 2,000 rpm), for $5 \mathrm{~min}$ first to drive out air pockets, and once more for $2 \mathrm{~min}$ to level the cream in the syringe. The syringes were then assembled and their contents were adjusted to the $1-\mathrm{mL}$ mark. The syringe assembly was wiped and weighed again. Density of MultiBase was calculated as the Filled weight (g) - Empty weight $(\mathrm{g})$ per milliliter.

\section{Results}

The percentage of doses in which MultiBase cream was dispensed within $10 \%$ of the target dose volume is presented in Figure 1. The performance of each dispenser system is illustrated in Figures 2-4 (for 1-mL dose) and Figures 5-7 (for 4-mL dose), with reference to the $10 \%$ upper and lower limits from the target dose amount. A comparison of the average dose delivered by each operator and dispenser is shown in Figure 8.

The average applicator weights, amounts of residual cream, and delivered dose volumes are shown in Table 2. Data in Table 3 presents the potential waste and estimated overfill volume required for a 30-day supply of feminine cream, assuming a dosage $1 \mathrm{~mL}$ of cream applied once daily. Estimated fill volume for each test system was the sum of the dispensed amount and the residual cream in both applicator and loader. Total waste volume was the difference between the estimated fill volume and the prescribed amount, and was expressed as a percentage of $30 \mathrm{~mL}$ volume. Qualitative observations by the operators are presented in Table 4.

\subsection{Topi-CLICK ${ }^{\circledR}$ Perl $^{\text {TM }}$}

Topi-CLICK $^{\circledR}$ Perl $^{\text {TM }}$ delivered an accurate dose 87.8$88.3 \%$ of the time (Figure 1). There were few excursions outside the $10 \%$ reference range, primarily instances of under-dosing (Figures 2 \& 5). Dosing variation was consistent with an overall variance less than $7.0 \%$. Average dose volume dispensed by three operators was $0.94 \pm 0.06$ $\mathrm{mL}$ in $1-\mathrm{mL}$ test, and $3.77 \pm 0.24 \mathrm{~mL}$ in 4 - $\mathrm{mL}$ test (Table 2, Figure 8).

The Topi-CLICK ${ }^{\circledR}$ Perl $^{\text {TM }}$ system had the least amount of residual cream compared to other tested devices in this study 
(Tables 2 and 3). Data derived from 1-mL dose indicated that approximately $1.22 \mathrm{~mL}$ of MultiBase was wasted in the form of residual cream after completion of 30 doses (Table 3 ). To compensate for this residual waste additional $5.5 \%$ of the 30 $\mathrm{mL}$ prescribed amount was deemed necessary to overfill the Topi-CLICK ${ }^{\circledR}$ loader for $1 \mathrm{~mL}$ daily dosage (Table 3 ).

Operator observations of the Topi-CLICK ${ }^{\circledR}$ Perl $^{\mathrm{TM}}$ system were primarily positive (Table 4). All operators considered the device easy to use. One operator did say that the applicator came off unexpectedly, but other operators liked that it was easy to attach and remove the applicators although some cream was observed at the port after removing the applicator. In addition, the operator in 4-mL test complained that it was difficult to keep count of the correct number of clicks, and how quickly to click.

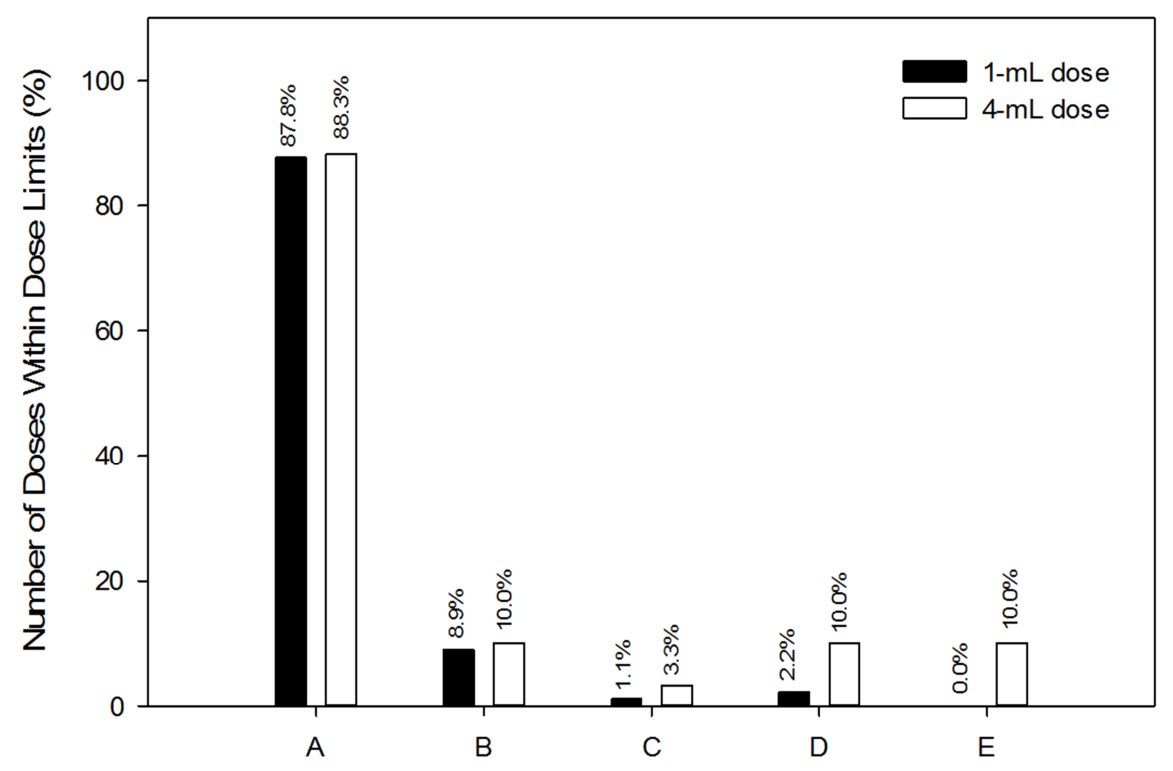

Figure 1. Percentage of total doses dispensed within $\pm 10 \%$ of target for $\square$ 1-mL and $\square$ 4-mL tests. A) Topi-CLICK ${ }^{\circledR}$ Perl ${ }^{\mathrm{TM}}$; B) Plastic tube/Ribbed applicator; C) Plastic tube/Smooth applicator; D) Metal (aluminum) tube/Ribbed applicator; E) Metal (aluminum) tube/Smooth applicator. Data shows Topi$C_{\text {LICK }}^{\mathbb{R}}$ Perl $^{\mathrm{TM}}$ out-performed other conventional dispensers in dosing accuracy for both 1-mL and 4-mL tests by a wide margin.

\subsection{Plastic Ointment Tube}

Regardless of applicator type, users of plastic tubes had a tendency towards overdosing (Figures $3 \& 6$ ). They also had few deliveries within $10 \%$ of the target dose, and high variations in the dispensed dose volumes. Plastic tubes had about $3.55 \pm 1.81 \mathrm{~mL}$ of residual cream compared to $2.24 \pm$ $0.13 \mathrm{~mL}$ for Topi-CLICK ${ }^{\circledR}$ Perl $^{\mathrm{TM}}$ (Table 3).

Users of the plastic tube \& ribbed applicator system had an overall dosing accuracy of $8.9-10.0 \%$ (Figure 1). Dosing variability was higher than the Topi-CLICK ${ }^{\circledR}$ Perl $^{\text {TM }}$ with an overall variance $9.3 \%$, and average dose volume was between 1.17-1.20 mL (Figure 8). The mean dose delivered by all users was $1.18 \pm 0.11 \mathrm{~mL}$ and $4.46 \pm 0.25 \mathrm{~mL}$, respectively in $1-\mathrm{mL}$ and $4-\mathrm{mL}$ tests (Table 2). The ribbed applicators had $0.09 \pm 0.02 \mathrm{~mL}$ of residual cream and an estimated waste volume $2.84 \mathrm{~mL}$ per 30 doses (Tables $2 \&$ 3 ). The total estimated waste was $11.85 \mathrm{~mL}$ requiring $39.5 \%$ of additional cream to fill a 30-day prescription for $1 \mathrm{~mL}$ daily dosage (Table 3).

Dosing accuracy for users of the plastic tube \& smooth applicator system was 1.1-3.3\% (Figure 1). Average dose for three operators in 1-mL test ranged between 1.39-1.42 mL with an overall variance $11.4 \%$ (Figure 8 ). The mean dose delivered by all users was $1.40 \pm 0.16 \mathrm{~mL}$ and $4.64 \pm 0.12$ $\mathrm{mL}$, respectively for $1-\mathrm{mL}$ and $4-\mathrm{mL}$ tests. The smooth applicator had $0.16 \pm 0.01 \mathrm{~mL}$ of residual cream and an estimated waste volume of $4.80 \mathrm{~mL}$ over 30 doses, or $16.0 \%$ of a $30-\mathrm{mL}$ prescription (Table 3). Approximately $20.40 \mathrm{~mL}$ of cream was wasted using plastic tube $\&$ smooth applicator combination, requiring $68.0 \%$ of additional cream to fill a 30-day prescription for $1 \mathrm{~mL}$ daily dosage.

Operator observations regarding the plastic tubes reflect difficulty with their use (Table 4). Plastic tubes required constant priming to prevent formation of air pockets. Air in the tube could cause the plunger in the applicator to "shoot up", or the tube may "rebound" once pressure was released pulling cream back inside the tube. Applying sufficient pressure to deliver cream volume within the target range was difficult, especially as the tube's content was lower towards the end of the cycle. Operators complained that squeezing hurt their hands and applicators fell off the tube during loading.

\subsection{Metal (Aluminum) Ointment Tube}

Users of the metal tube had a tendency to overdose with both ribbed and smooth applicators (Figures $4 \& 7$ ). There were no instances of under-dosing with the metal tubes, and dosing within range was quite rare. Metal tubes had about $5.07 \mathrm{~mL}$ of MultiBase remaining after use, which was the highest volume of residual cream among the systems tested in this study (Table 3). 


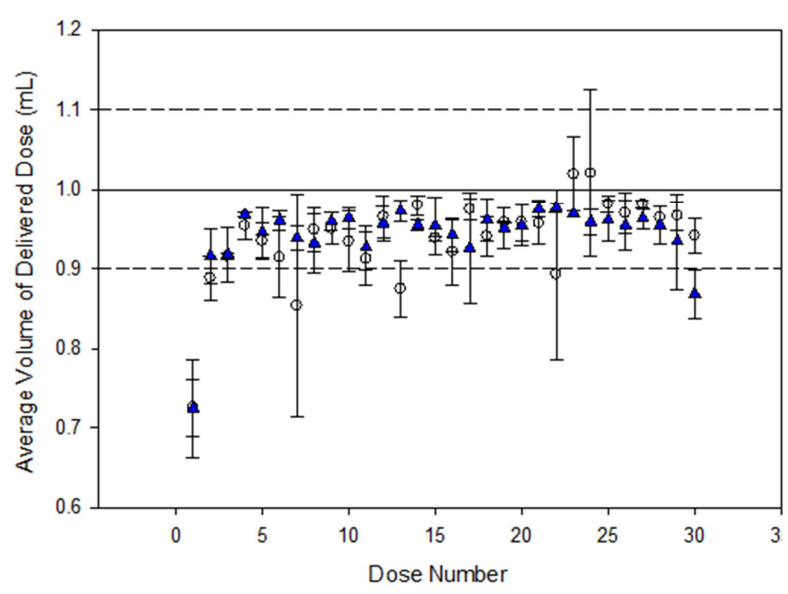

Figure 2. Performance chart for the Topi-CLICK ${ }^{\circledR}$ Perl ${ }^{\mathrm{TM}}$ in 1-mL test (Error bars are $S D$ for $n=3$ users.) - 1-mL Target dose; --- $\pm 10 \%$ acceptable dose limits. Data shows majority of doses from both Set 1( o ) and Set 2 (4) were within the acceptable dose limits.

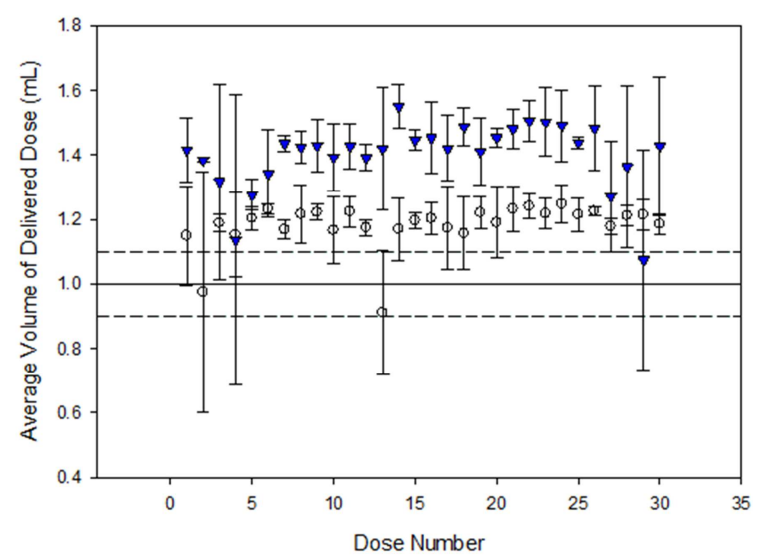

Figure 3. Performance charts for the Plastic Tube dispenser systems in 1$m L$ test (Error bars are SD for $n=3$ users.) - 1-mL Target dose; ---- $\pm 10 \%$ acceptable dose limits. Data shows majority of doses from both Plastic tube/Ribbed applicator ( o ) and Plastic tube/Smooth applicator ( $\mathbf{\Delta}$ ) were outside the acceptable dose limits compared to Topi-CLICK ${ }^{\circledR}$ Perl $^{\mathrm{TM}}$.

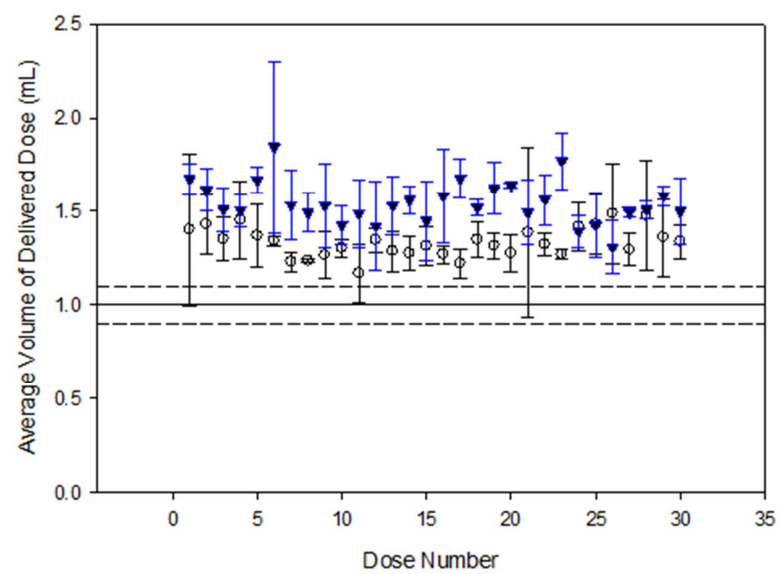

Figure 4. Performance charts for the Metal Tube dispenser systems in 1-mL test (Error bars are SD for $n=3$ users.) - 1-mL Target dose; --- $\pm 10 \%$ acceptable dose limits. Data shows majority of doses from both Metal tube/Ribbed applicator ( $\mathrm{o}$ ) and Metal tube/Smooth applicator ( $\mathbf{\Delta}$ ) were outside the acceptable dose limits compared to Topi-CLICK ${ }^{\mathbb{R}}$ Perl $^{\mathrm{TM}}$.

Operators of the metal tube \& ribbed applicator system had an overall dosing accuracy of 2.2-10\% (Figure 1). Dose volumes varied among three operators and average dose range was $1.28-1.41 \mathrm{~mL}$ in $1-\mathrm{mL}$ dose test (Figure 8). The overall mean volume dispensed was $1.33 \pm 0.16 \mathrm{~mL}$ and 4.58 $\pm 0.22 \mathrm{~mL}$, respectively for $1-\mathrm{mL}$ and $4-\mathrm{mL}$ dose tests (Table 2). Average residual cream for ribbed-applicators was $0.10 \pm$ $0.02 \mathrm{~mL}$ with an estimated waste of $3.02 \mathrm{~mL}$ for 30 doses (Table 3). The metal tube \& ribbed applicator combination has an overall waste potential of $18.10 \mathrm{~mL}$, requiring $60.3 \%$ overfill volume for a 30-day supply of $1 \mathrm{~mL}$ daily dosage (Table 3).

Users of the metal tube \& smooth applicator system had an overall dosing accuracy of $0.0-10.0 \%$ (Figure 1). In the $1-\mathrm{mL}$ dose test, it completely failed to deliver a dose within $10 \%$ of the target (Figure 1). This combination also had high dosing variability with average dose volume $1.54 \pm 0.17 \mathrm{~mL}$ and $11.0 \% \mathrm{CV}$ in $1-\mathrm{mL}$ test. Among three operators, average dose ranged between $1.50-1.60 \mathrm{~mL}$ and $4.76 \pm 0.25 \mathrm{~mL}$, respectively for $1-\mathrm{mL}$ and $4-\mathrm{mL}$ tests (Figure 8 ). In addition, this dispenser system had high residual waste at $0.16 \pm 0.01$ $\mathrm{mL}$ per dose in 1-mL test, and an estimated waste of $4.86 \mathrm{~mL}$ over 30 doses (Table 3 ). The total system waste was estimated at $26.28 \mathrm{~mL}$, so this combination would require an extra $87.6 \%$ of cream to fill a 30-day prescription for $1 \mathrm{~mL}$ daily dosage (Table 3 ).

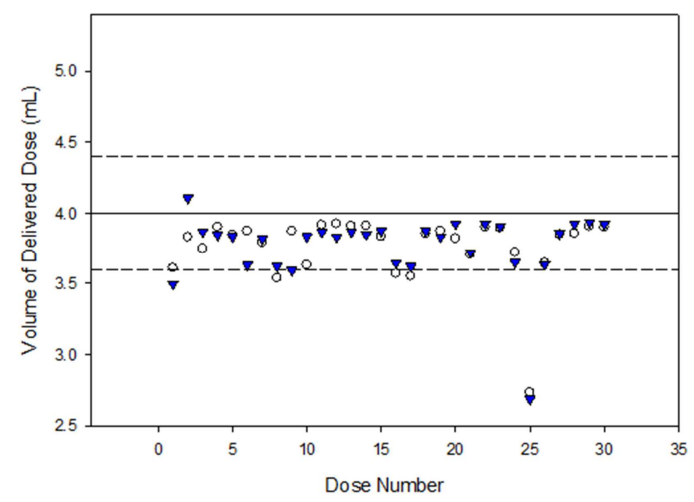

Figure 5. Performance chart for the Topi-CLICK ${ }^{\circledR}$ Perl $^{\mathrm{TM}}$ in 4-mL test. - 4$m L$ Target dose; ---- $\pm 10 \%$ acceptable dose limits. Similar dispensing patterns were observed for Set 1 ( o ) and Set $2(\mathbf{\Delta})$ compared to 1-mL test.

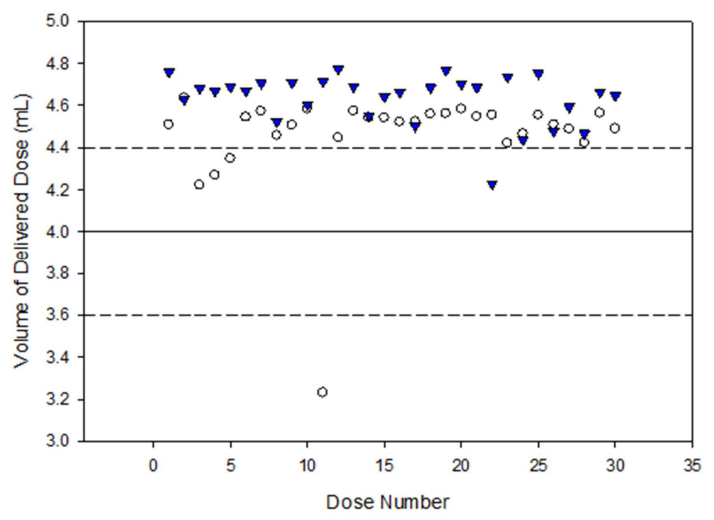

Figure 6. Performance chart for the Plastic Tube dispenser systems in 4-mL test. - 4-mL Target dose; ---- $\pm 10 \%$ acceptable dose limits. Similar dispensing patterns were observed for both Plastic tube/Ribbed applicator (o) and Plastic tube/Smooth applicator (4) compared to 1-mL test. 


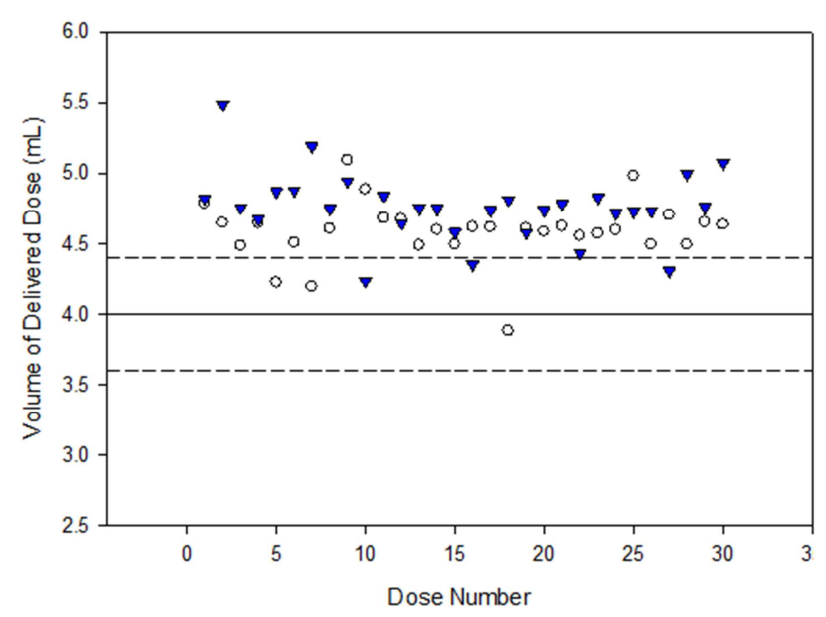

Figures 7. Performance chart for the Metal Tube dispenser systems in 4-mL test. - 4-mL Target dose; ---- $\pm 10 \%$ acceptable dose limits. Similar dispensing patterns were observed for both Metal tube/Ribbed applicator ( o ) and Metal tube/Smooth applicator (4) compared to 1-mL test.

Operator observations reflect significant difficulty in using metal tube systems (Table 4). The metal tubes tended to split at the seams from which cream exuded causing operation to be messy; the content continued to leak through the split even after pressure was released. While the fact that metal tubes did not require constant priming was considered positively, operators complained that squeezing hurt their hands and applicators did not always stay on the dispenser.

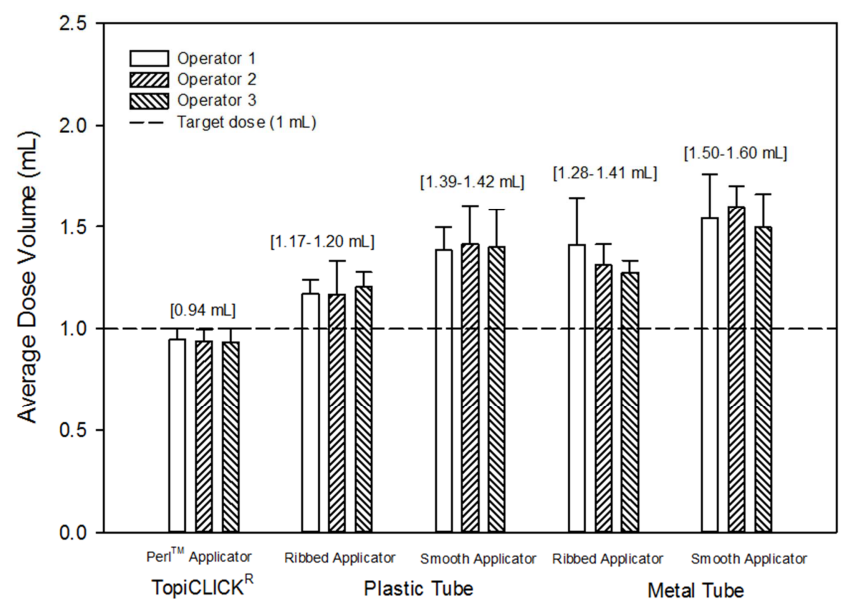

Figure 8. Dosing precision for the operators in 1-mL test. Error bars are standard deviation (SD, $N=60$ for TopiCLICK ${ }^{\circledR}$ Perl $^{T M} ; N=30$ for Plastic and Metal tube systems). Values in brackets represent range of mean dose volume for each system. Data shows overdosing tendency with high variability among operators of both plastic and metal ointment tubes systems.

\section{Discussion}

Plastic ointment tubes offer some advantages over other types such as being chemically resistant, collapsible and light [14]. One of the problems found when using plastic tubes was the formation of air pockets after a couple of doses. This could be due to the tube's ability for regaining its original shape which lets air back inside the tube. Thus, the need for priming was more prevalent using plastic tubes than with the Topi-CLICK $^{\circledR}$ Perl $^{\text {TM }}$ or the metal aluminum ointment tube systems. This issue had led to diminished accuracy and precision of the delivered doses, less user-friendly compared to the Topi-CLICK ${ }^{\circledR}$ Perl $^{\mathrm{TM}}$, and could inadvertently expose drug to air and contaminants.

Metal (aluminum) ointment tube was chosen as one of the loaders due to the vast amounts of topical medications already available in metal tubes. Its characteristics are appropriate for such: it has the ability to be bent or folded without allowing the walls to recover their original shape [14]. This makes it easier to determine the relative amount of medication remaining after each use. However, one of the main concerns with metal tubes was leakiness since they have the tendency to break along the seams. This may be due to the force that was applied to the tubes, which could be related to the user's complaint that the pressure needed to squeeze the cream out was more than that experienced using other test systems. As a result, dosing accuracy and precision was diminished relative to the Topi-CLICK ${ }^{\circledR}$ Perl $^{\mathrm{TM}}$. The operators also reported that cream was still being dispensed from the tubes after squeezing was stopped which led to a messier situation that would reduce patient satisfaction. This also leads to more drug being wasted and contributes negatively to the accuracy and precision of the delivered dose. However, metal ointment tubes are impermeable to gases and shatterproof, which contributes to drug stability and safety [14].

Metered dosing systems have been used with ease and are effective when used appropriately in certain chronic disease management [15]. The Topi-CLICK ${ }^{\circledR}$ Perl $^{\text {TM }}$ system was given the best qualitative comments out of other systems tested in this study. Problems reported by the operators were large number of clicks in dispensing 4-mL dose, and the waiting time between clicks. These issues are certainly challenges associated with dose larger than $1 \mathrm{~mL}$ using TopiCLICK $^{\circledR}$ Perl $^{\mathrm{TM}}$ in its current format. Despite these challenges, test results favored the Topi-CLICK ${ }^{\circledR}$ Perl $^{\mathrm{TM}}$ system over other conventional ointment tube systems for all measures.

According to Figure 1, the percentage of doses that were delivered within the $10 \%$ margin was highest using the TopiCLICK $^{\circledR}$ Perl $^{\text {TM }}$ vaginal dosing system. This could be due to the ease of administration experienced by the operators with minimal mess. Data in Figure 2 supports the accuracy of Topi-CLICK $^{\circledR}$ Perl $^{\mathrm{TM}}$ with majority of doses being delivered within the targeted range. Whereas Figures 3 and 4 show both plastic and metal ointment tubes exhibited a tendency for overdosing; they demonstrated a wide range of delivered dose volumes creating potential problems with drugs that have narrow therapeutic ranges. A possible confounding factor that could contribute to this problem is the pressure that must be applied to dispense the desired amount of cream, especially towards the end of the dosing cycle- when there is less cream remained in the tubes, it was harder to squeeze correct amount from them for dosing. Figure 2 also shows Topi-CLICK $^{\circledR}$ Perl $^{\mathrm{TM}}$ had few doses being out-of-range, and 
although these instances were rare it could be related to errors in tracking number of clicks required for dosing.

Tables 3 shows the average amount of residual cream as well as the estimated total volume of extra medicinal cream required to complete the therapy. Plastic and metal ointment tubes equipped with the smooth applicators had higher percentage of residual cream than their ribbed counterparts. However, all of them substantially had more residual cream than the Topi-CLICK ${ }^{\circledR}$ Perl $^{\mathrm{TM}}$, which is due to an excess of cream being dispensed for reasons mentioned earlier using metal and plastic tubes.

\section{Conclusion}

The Topi-CLICK ${ }^{\circledR}$ Perl $^{\text {TM }}$ system performed with a high level of accuracy and precision in delivering doses of feminine creams, outperforming other tested devices in all measures. Traditional metal and plastic tubes both failed to demonstrate dosing accuracy. They had a marked tendency toward overdosing and high variability among operators.

Regarding residual and waste, the Topi-CLICK ${ }^{\circledR}$ Perl $^{\mathrm{TM}}$ had the least residual cream in both the Topi-CLICK ${ }^{\circledR}$ Perl $^{\mathrm{TM}}$ loader and the Perl $^{\mathrm{TM}}$ applicator. Smooth applicators had a higher amount of wasted cream than ribbed applicators. A combination of metal ointment tube and smooth applicator had much more residual waste that would need larger overfill volume relative to the Topi-CLICK ${ }^{\circledR}$ Perl $^{\mathrm{TM}}$ for the same prescription. The metal ointment tubes were messy and continued to dispense after pressure was released, and plastic tubes required regular priming. Operators considered Topi$\mathrm{CLICK}^{\circledR}$ Perl $^{\mathrm{TM}}$ the easiest to use showing good potential for the metered-dosing system to be utilized with feminine medications for intra-vaginal drug administration.

Table 2. Average fill volume, volume of residual cream, and delivered dose volume for Topi-CLICK ${ }^{\circledR}$ Perl ${ }^{\mathrm{TM}}$, Smooth, and Ribbed applicators. Values in parenthesis are standard deviations (SD).

\begin{tabular}{|c|c|c|c|c|c|c|c|}
\hline Vaginal Dosing System & Dose & $\begin{array}{l}\text { Start Weight } \\
(\mathrm{g})\end{array}$ & $\begin{array}{l}\text { Filled Weight } \\
(\mathrm{g})\end{array}$ & $\begin{array}{l}\text { Fill Volume } \\
(\mathrm{mL})\end{array}$ & $\begin{array}{l}\text { Empty } \\
\text { Weight (g) }\end{array}$ & $\begin{array}{l}\text { Residual } \\
(\mathrm{mL})\end{array}$ & $\begin{array}{l}\text { Delivered Dose } \\
(\mathrm{mL})\end{array}$ \\
\hline \multirow{2}{*}{ 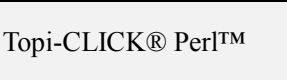 } & $1 \mathrm{~mL}$ & $5.36(0.01)$ & $6.27(0.06)$ & $0.98(0.06)$ & $5.40(0.02)$ & $0.04(0.01)$ & $0.94(0.06)$ \\
\hline & $4 \mathrm{~mL}$ & $5.36(0.01)$ & $8.98(0.23)$ & $3.92(0.25)$ & $5.50(0.04)$ & $0.16(0.04)$ & $3.77(0.24)$ \\
\hline \multirow{2}{*}{$\begin{array}{l}\text { Plastic Tube, Ribbed } \\
\text { Applicator }\end{array}$} & $1 \mathrm{~mL}$ & $7.71(0.04)$ & $8.89(0.11)$ & $1.28(0.11)$ & $7.80(0.04)$ & $0.09(0.02)$ & $1.18(0.11)$ \\
\hline & $4 \mathrm{~mL}$ & $7.69(0.03)$ & $12.02(0.25)$ & $4.69(0.25)$ & $7.91(0.09)$ & $0.23(0.09)$ & $4.46(0.25)$ \\
\hline \multirow{2}{*}{$\begin{array}{l}\text { Plastic Tube, Smooth } \\
\text { Applicator }\end{array}$} & $1 \mathrm{~mL}$ & $7.02(0.06)$ & $8.46(0.18)$ & $1.56(0.16)$ & $7.17(0.06)$ & $0.16(0.01)$ & $1.40(0.16)$ \\
\hline & $4 \mathrm{~mL}$ & $7.03(0.06)$ & $11.48(0.14)$ & $4.82(0.12)$ & $7.19(0.05)$ & $0.18(0.02)$ & $4.64(0.12)$ \\
\hline \multirow{2}{*}{$\begin{array}{l}\text { Metal Tube, Ribbed } \\
\text { Applicator }\end{array}$} & $1 \mathrm{~mL}$ & $7.71(0.04)$ & $9.04(0.15)$ & $1.43(0.16)$ & $7.80(0.05)$ & $0.10(0.02)$ & $1.33(0.16)$ \\
\hline & $4 \mathrm{~mL}$ & $7.70(0.04)$ & $12.18(0.38)$ & $4.85(0.41)$ & $7.95(0.27)$ & $0.27(0.31)$ & $4.58(0.22)$ \\
\hline \multirow{2}{*}{$\begin{array}{l}\text { Metal Tube, Smooth } \\
\text { Applicator }\end{array}$} & $1 \mathrm{~mL}$ & $7.00(0.06)$ & $8.58(0.18)$ & $1.71(0.17)$ & $7.15(0.06)$ & $0.16(0.01)$ & $1.54(0.17)$ \\
\hline & $4 \mathrm{~mL}$ & $7.03(0.07)$ & $11.60(0.24)$ & $4.94(0.25)$ & $7.20(0.06)$ & $0.18(0.02)$ & $4.76(0.25)$ \\
\hline
\end{tabular}

Table 3. Average residual cream and the estimated extra medicine required to fill 30-day supply for $1 \mathrm{~mL}$ daily dosage.

\begin{tabular}{|c|c|c|c|c|c|}
\hline Parameter Average & $\begin{array}{l}\text { Topi-CLICK } \\
\text { Perl }^{\circledR \mathrm{T}} \\
\end{array}$ & $\begin{array}{l}\text { Plastic tube, } \\
\text { Ribbed applicator }\end{array}$ & $\begin{array}{l}\text { Plastic tube, } \\
\text { Smooth applicator }\end{array}$ & $\begin{array}{l}\text { Metal tube, Ribbed } \\
\text { applicator }\end{array}$ & $\begin{array}{l}\text { Metal Tube, } \\
\text { Smooth applicator }\end{array}$ \\
\hline \multicolumn{6}{|l|}{ Dose delivered } \\
\hline Per dose & $0.94 \mathrm{~mL}$ & $1.18 \mathrm{~mL}$ & $1.40 \mathrm{~mL}$ & $1.33 \mathrm{~mL}$ & $1.54 \mathrm{~mL}$ \\
\hline 30 doses & $28.19 \mathrm{~mL}$ & $35.46 \mathrm{~mL}$ & $42.05 \mathrm{~mL}$ & $40.01 \mathrm{~mL}$ & $46.35 \mathrm{~mL}$ \\
\hline \multicolumn{6}{|l|}{ Applicator residual } \\
\hline Per dose & $0.04 \mathrm{~mL}$ & $0.09 \mathrm{~mL}$ & $0.16 \mathrm{~mL}$ & $0.10 \mathrm{~mL}$ & $0.16 \mathrm{~mL}$ \\
\hline 30 doses & $1.22 \mathrm{~mL}$ & $2.84 \mathrm{~mL}$ & $4.80 \mathrm{~mL}$ & $3.02 \mathrm{~mL}$ & $4.86 \mathrm{~mL}$ \\
\hline Loader residual & $2.24 \mathrm{~mL}$ & $3.55 \mathrm{~mL}$ & $3.55 \mathrm{~mL}$ & $5.07 \mathrm{~mL}$ & $5.07 \mathrm{~mL}$ \\
\hline Estimated fill volume for 30 doses & $31.66 \mathrm{~mL}$ & $41.85 \mathrm{~mL}$ & $50.40 \mathrm{~mL}$ & $48.10 \mathrm{~mL}$ & $56.28 \mathrm{~mL}$ \\
\hline Total waste volume & $1.65 \mathrm{~mL}$ & $11.85 \mathrm{~mL}$ & $20.40 \mathrm{~mL}$ & $18.10 \mathrm{~mL}$ & $26.28 \mathrm{~mL}$ \\
\hline $\begin{array}{l}\text { Additional medicine needed per } 30 \mathrm{~mL} \\
\text { prescription }(\%)\end{array}$ & $5.5 \%$ & $39.5 \%$ & $68.0 \%$ & $60.3 \%$ & $87.6 \%$ \\
\hline
\end{tabular}

Table 4. Qualitative observations regarding the ease of use, accuracy and waste of each dispensing system.

\begin{tabular}{|c|c|c|c|}
\hline Dispenser & Ease of Use & Accuracy & Waste \\
\hline $\begin{array}{l}\text { Topi-CLICK } \\
\text { Perl }^{\text {TM }}\end{array}$ & $\begin{array}{l}\text { Very easy to use physically Only have to worry about } \\
\text { the number of clicks and waiting } 2 \text { min after dispensing } \\
\text { to remove the applicator Knocked the applicator off the } \\
\text { loader a couple of times Was unsure how fast to click } \\
\text { for dispensing A little cream was left after moving the } \\
\text { applicator and wiped it with a Kimwipe It was always } \\
\text { easy to get the cream out It is easy to get the applicators } \\
\text { on and off Relieved with its ease of use However, } 16 \\
\text { clicks is a lot and one could lose count-which happened } \\
\text { a couple of times. Again not sure if clicking too fast. }\end{array}$ & $\begin{array}{l}\text { The Perl }{ }^{\mathrm{TM}} \text { system was the only one where I } \\
\text { didn't run out of cream earlier than } \\
\text { expected It is the best loader and applicator } \\
\text { because there is no defect in design }\end{array}$ & \\
\hline
\end{tabular}




\begin{tabular}{|c|c|c|c|}
\hline Dispenser & Ease of Use & Accuracy & Waste \\
\hline $\begin{array}{l}\text { Plastic Tube, } \\
\text { Smooth } \\
\text { Applicator }\end{array}$ & $\begin{array}{l}\text { The applicator is easy to quickly click on and off A little } \\
\text { bit of cream is left after removing the applicator } \\
\text { When cream levels were low, it was hard to physically } \\
\text { apply enough and even pressure across the tube to } \\
\text { dispense the cream properly Also, while the cream was } \\
\text { at a low level, pressure had to be maintained while } \\
\text { removing the applicators. Otherwise, the rebound with } \\
\text { the plastic would suck cream back into the loader Four } \\
\text { times the plunger jumped up high when pressure was } \\
\text { applied to the tube It hurts one's hands to squeeze the } \\
\text { tube. It was hard to deliver the doses Twice, the plunger } \\
\text { of the applicator shot up to the middle of the barrel } \\
\text { while trying to deliver a dose One applicator was hard } \\
\text { to screw onto the tube Notice that if the applicator is } \\
\text { screwed on tight, it was harder to squeeze out the } \\
\text { cream. This was true for both the smooth and ribbed } \\
\text { applicators and happened also with the } 1 \text { mL doses } \\
\text { Again, it was hard to apply enough/even pressure when } \\
\text { the loaders were low to dispense cream and avoid } \\
\text { rebound effect If not primed, air shoots the plungers } \\
\text { upward }\end{array}$ & $\begin{array}{l}\text { After dispensing a few doses, air pockets } \\
\text { started to form in the tube. Thus, the whole } \\
\text { time, the plastic loaders had to be primed } \\
\text { before dispensing Doses look smaller than } \\
\text { with the ribbed applicators Air pockets } \\
\text { form after first few dispenses. Constantly } \\
\text { need to prime the tube/purge the tube of air } \\
\text { before trying to dispense into the applicator }\end{array}$ & \\
\hline $\begin{array}{l}\text { Plastic Tube, } \\
\text { Ribbed } \\
\text { Applicator }\end{array}$ & $\begin{array}{l}\text { It was physically difficult/challenging to apply enough } \\
\text { even pressure to dispense when cream levels were low } \\
\text { and challenging to avoid rebound } \\
\text { Twice, it was hard to get the cream into the applicator } \\
\text { Twice, the plunger suddenly jumped up high when } \\
\text { pressure was applied to the tube Some doses were hard } \\
\text { to deliver. It hurts one's hands to squeeze the tube Need } \\
\text { constant priming }\end{array}$ & $\begin{array}{l}\text { After dispensing a few doses, air pockets } \\
\text { started to form. Thus, the whole time, the } \\
\text { plastic loaders had to be primed before } \\
\text { dispensing If the tubes were not primed } \\
\text { before dispensing, air in the tube would } \\
\text { cause the plunger of the applicator to shoot } \\
\text { upwards If air is not removed by priming } \\
\text { before the dose, the plunger shoots upward } \\
\text { (sometimes across the room) }\end{array}$ & \\
\hline $\begin{array}{l}\text { Metal Tube, } \\
\text { Smooth } \\
\text { Applicator }\end{array}$ & $\begin{array}{l}\text { This loader applicator combination seemed messier } \\
\text { (rips in the loader and extra cream dispensed) Had to } \\
\text { squeeze hard to get the cream out of the tube, and hands } \\
\text { got tired Some doses were difficult to deliver }\end{array}$ & $\begin{array}{l}\text { Metal loaders kept dispensing cream after } \\
\text { pressure was no longer applied on the tube. } \\
\text { This probably caused over-filling or at } \\
\text { least, cream being wasted Priming was } \\
\text { easier to maintain in metal, compared to } \\
\text { plastic, loaders. There was no rebound with } \\
\text { metal loaders Cream continues to dispense } \\
\text { after pressure is no longer applied Priming } \\
\text { easier to maintain and no rebound as with } \\
\text { the plastic loaders }\end{array}$ & $\begin{array}{l}\text { Two metal loaders ripped on } \\
\text { the side. This was due to } \\
\text { rolling up the tubes (similar to } \\
\text { what someone may do with a } \\
\text { toothpaste tube) Towards the } \\
\text { end of the tube when most } \\
\text { cream was out, holes appeared } \\
\text { in the sides of some tubes One } \\
\text { tube developed a hole in its } \\
\text { side and cream came out } \\
\text { Twice, extra cream oozed out } \\
\text { of the tube after the applicator } \\
\text { was removed Metal loaders } \\
\text { still ripping when rolling up } \\
\text { the tube. But, this seems to be } \\
\text { the best way to dispense all } \\
\text { contents. However, it's still } \\
\text { messy Needs to be capped } \\
\text { quickly after the applicator is } \\
\text { removed }\end{array}$ \\
\hline $\begin{array}{l}\text { Metal Tube, } \\
\text { Ribbed } \\
\text { Applicator }\end{array}$ & $\begin{array}{l}\text { Had to squeeze hard to get the cream out of the tube, } \\
\text { and hands got tired Two applicators fell off the tube } \\
\text { when delivering a dose }\end{array}$ & $\begin{array}{l}\text { Metal tubes kept dispensing cream after } \\
\text { pressure was no longer applied. Had to } \\
\text { take the applicator off quickly and cap the } \\
\text { tube quickly to stop the cream from } \\
\text { coming out } \\
\text { Once, the plunger jumped up while } \\
\text { delivering a dose A number of times, } \\
\text { cream still came out of tubes after taking } \\
\text { off the applicator One time, the plunger of } \\
\text { the applicator shot up to the middle of the } \\
\text { barrel while trying to deliver a dose Needs } \\
\text { to be capped quickly after the applicator is } \\
\text { removed. Cream continues to be dispensed } \\
\text { after pressure is no longer applied }\end{array}$ & $\begin{array}{l}\text { Keeping metal tubes primed } \\
\text { was easier, but rolling up the } \\
\text { tubes caused rips in the tubes. } \\
\text { This made things } \\
\text { messierTowards the end of the } \\
\text { tube when most cream was } \\
\text { out, holes appeared in the sides } \\
\text { of some tubes Five times, the } \\
\text { extra cream oozed out of the } \\
\text { tube after the applicator was } \\
\text { removed No need to constantly } \\
\text { prime, but rolling technique } \\
\text { still results in messy clean up }\end{array}$ \\
\hline
\end{tabular}




\section{Acknowledgements}

This study was supported in part through a grant by DoseLogix. We would like to thank Matthew Beyer, Quality Control Engineer at DoseLogix for his comments and critical readings of this manuscript.

\section{References}

[1] Vermani K, Garg S. The Scope and Potential of Vaginal Drug Delivery. Pharmaceutical Science \& Technology Today. 2000; 3 (10): 359-364.

[2] Mazloomdoost D, Westermann LB, Mutema G, et al. Histologic Anatomy of the Anterior Vagina and Urethra. Female Pelvic Medicine \& Reconstructive Surgery. 2017; 23 (5): 329-335.

[3] Srikrishna S, Cardozo L. The Vagina as a Route for Drug Delivery: A Review. Int Urogynecol J. 2013 Apr; 24 (4): 53743.

[4] Sahoo CK, Nayak PK, Sarangi DK, Sahoo TK. Intra Vaginal Drug Delivery System: An Overview. American Journal of Advanced Drug Delivery. 2013; 1: 43-55.

[5] Gupta S, Prabha V. Intravaginal Delivery Approaches for Contraception: An Overview with Emphasis on Gels. J Pharm Pharm Sci. 2017; 20 (0): 270-284.

[6] Fraser IS, Mansour D. Delivery Systems for Hormone Replacement Therapy. Expert Opin Drug Deliv. 2006 Mar; 3 (2): 191-204.
[7] McConville C. The Therapeutic Potential of Vaginal Drug Delivery in the Treatment of Cervical Cancer. Ther Deliv. $2015 \mathrm{Jul} ; 6$ (7): 888.

[8] Sawant B, Khan T. Recent Advances in Delivery of Antifungal Agents for Therapeutic Management of Candidiasis. Biomed Pharmacother. 2017 Dec; 96: 1478-1490.

[9] Nel A, Niekerk N, Kapiga S, et al. Safety and Efficacy of a Dapivirine Vaginal Ring for HIV Prevention in Women. The New England Journal of Medicine. 2016; 375 (22): 21332143.

[10] Brown MT, Bussell JK. Medication Adherence: Who Cares? Mayo Clin Proc. 2011 April; 86 (11): 304-314.

[11] Zullig LL, Bosworth H. Engaging patients to Optimize Medications Adherence. May 14, 2017. https://catalyst.nejm.org/optimize-patients-medicationadherence/.

[12] Kim J, Combs K, Downs J. Tillman III F. Medication Adherence: The Elephant in the Room. Jan 19, 2018. https://www.uspharmacist.com/article/medication-adherencethe-elephant-in-the-room.

[13] Estradiol (topical) monograph. Lexi-Comp Online, LexiDrugs Online, Hudson, Ohio: Lexi-Comp Inc., 2004, October $16,2018$.

[14] Anand S, Mane D. Collapsible Tube for Pharmaceutical Use. International Journal of Pharmaceutical and Chemical Sciences. 2014; 3 (2): 291-398.

[15] Guidelines on Packaging for Pharmaceuticcal Products. World Health Organization. 2002; 902: 119-156. 